\title{
Effect of Different Scaling Methods and Materials on the Enamel Surface Topography: An In Vitro SEM Study
}

\author{
Mahmoud Al Ankily ${ }^{1}$, Fatma Makkeyah'², Mahmoud M. Bakr ${ }^{3}$, Mohamed Shamel ${ }^{1}$ \\ ${ }^{1}$ Department of Oral Biology, The British University in Egypt, Cairo, Egypt, ${ }^{2}$ Department of Fixed Prosthodontics, The British University in Egypt, Cairo, Egypt, ${ }^{3}$ Clinical \\ Education, School of Dentistry and Oral Health, Griffith University, Gold Coast, Queensland, Australia
}

\section{Abstract}

Aim: Scaling is important for maintenance of gingival and periodontal conditions. These procedures have a harmful effect on the dental hard tissues. The aim of this study was to investigate the effects of hand and ultrasonic instruments made of stainless and titanium on the surface properties of enamel. Materials and Methods: Forty extracted premolars were used in this in vitro study and were randomly divided into four groups $(n=10)$. Group I received ultrasonic scaling with stainless steel tip, group II received ultrasonic scaling with titanium tip, group III hand scaling with stainless steel tip, and group IV hand scaling with titanium tip. Scanning electron microscopy (SEM) was used to examine the enamel surface morphology. Surface roughness of enamel was measured at baseline and after the scaling simulation using atomic force microscopy (AFM). Differences between initial and final measurements of surface roughness $(\Delta \mathrm{Ra})$ were analyzed using two-way analysis of variance (ANOVA) followed by post hoc pairwise comparisons between groups. Results: SEM revealed deeper scratches and more destructive changes on enamel surface in group IV, whereas other groups revealed less change. AFM revealed that a mean surface roughness difference $(\Delta R a)$ had the highest value with hand instruments using titanium curettes, whereas the lowest difference was found with ultrasonic tips using stainless-steel tips. Hand titanium curettes showed a statistically significant increase in $\Delta \mathrm{Ra}$ when compared to hand stainless steel curettes $(P=0.02)$ and ultrasonic titanium tips $(P=0.01)$. Hand stainless steel tips showed a statistically significant increase in $\Delta$ Ra when compared to ultrasonic stainless steel tips $(P=0.02)$ and hand titanium curettes $(P=0.02)$. Conclusion: Scaling using ultrasonic stainless steel tips produce the least amount of surface roughness and damage to the tooth surface.

Keywords: Atomic Force Microscopy, Electron Microscopy, Enamel, Scaling, Surface Roughness

Received: 05-04-2020, Revised: 06-04-2020, Accepted: 13-07-2020, Published: 30-11-2020.

\section{INTRODUCTION}

Bacterial plaque or biofilms are described as organized structures consisting of microcolonies of bacterial cells, distributed in a shaped matrix or glycocalyx..$^{[1,2]}$ In relation to the oral cavity, it is termed dental plaque and it subsequently mineralizes to form hard deposits termed calculus. ${ }^{[3]}$ The majority of patients suffer from gingival inflammation in response to this plaque, which eventually progresses to periodontitis. Bone destruction and tooth loss are the main consequences following periodontitis which is considered one of the most common oral diseases. ${ }^{[4]}$ Successful management of the periodontal diseases is of great significance in preventing irreversible bone destruction and tooth loss. This is based on regulating the dental plaque and restriction of further progression of the disease. Different treatment methods such as standard

\begin{tabular}{|l|l|}
\hline \multicolumn{2}{|c|}{ Access this article online } \\
\hline Quick Response Code: & Website: \\
& www.jioh.org \\
\cline { 2 - 2 } & \\
\hline
\end{tabular}

nonsurgical strategies, gingival curettage, laser treatment, and regenerative procedures can be used. ${ }^{[5-10]}$

American Academy of Periodontology proposed that any procedures to maintain the gingival and periodontal health should be performed with minimally invasive techniques. ${ }^{[1]}$ These noninvasive treatment methods used to manage periodontal problems include scaling, root planning, and oral hygiene care and are extensively performed routinely in dental practice. The scaling procedure necessitates removal of bacterial plaque, hard calculus, and extrinsic stains from the surfaces of crown and root. ${ }^{[12]}$ Although

Address for correspondence: Dr. Mahmoud Al Ankily, 14 A Kawala St. Abdeen, Cairo 11613, Egypt. E-mail:mahmoud.ankily@bue.edu.eg

This is an open access journal, and articles are distributed under the terms of the Creative Commons Attribution-NonCommercial-ShareAlike 4.0 License, which allows others to remix, tweak, and build upon the work non-commercially, as long as appropriate credit is given and the new creations are licensed under the identical terms.

For reprints contact: reprints@medknow.com

How to cite this article: Al Ankily M, Makkeyah F, Bakr MM, Shamel M. Effect of different scaling methods and materials on the enamel surface topography: An in vitro SEM study. J Int Oral Health 2020;12:579-85. 
scaling is a very challenging procedure, its role in controlling gingivitis and periodontitis is well-documented. ${ }^{[13]}$

Scaling is carried out either with hand or ultrasonic scalers. The advantage of hand scaling involves superior management of the instruments and an improved tactile feedback to the operator. It is skill-dependent, time-consuming, and exhausting, whereas sonic and ultrasonic scalers allow access to the furcation and deep pockets and are more time efficient and less tiring to dental practitioners. ${ }^{[14,15]}$

The mechanism of ultrasonic scalers includes the vibrations that aids in biofilm removal and the acoustic effects of water lavage, and the mechanical chipping action of the oscillating scaler probe when in contact with the tooth surface which assists in the removal of calculus deposit. ${ }^{[16]}$ However, it has been reported that these power-driven scalers can cause roughness of enamel surfaces, a procedure that can be affected by many factors such as procedure time, pressure, and angulation of the scaling tip. ${ }^{[17,18]}$

Different materials of hand instruments and ultrasonic tips such as stainless steel curettes, rubber cups, plastic curettes, titanium curettes, and air-power abrasive systems have been used in removing plaque from tooth surfaces as well as implants. ${ }^{[19]}$ However, the scaling procedures with these materials can increase surface roughness of tooth surfaces and dental restorations, which will influence color stability and microbial colonization and induce plaque formation. A positive correlation between surface roughness and the rate of supragingival and subgingival plaque deposition has been reported. ${ }^{[20]}$

Stainless steel curettes are most commonly used for tooth scaling, whereas titanium-coated curettes are specifically made for dental implant debridement because they have a similar hardness to the titanium surface and will not scratch or mark the surface. ${ }^{[21]}$ However, the effect of the use of titanium instruments for tooth scaling has not been investigated. The aim of this study was to investigate the effect of different types of hand and ultrasonic instruments used in scaling on surface properties of enamel.

\section{Materials and Methods}

\section{Setting and design}

This study was conducted to evaluate the effect of two different scaling mechanisms: hand scaling and ultrasonic scaling with scaling instrument material stainless steel and titanium on the surface roughness and surface anatomy of enamel by using atomic force microscopy (AFM) and scanning electron microscopy (SEM).

\section{Sampling criteria}

Forty extracted sound human premolars were collected from patients with an average age from 14 to 20 years undergoing extractions for orthodontic purposes. Immediately after extraction, the teeth were scraped of any residual tissue, washed under running tap water, and examined for the presence of cracks or carious lesions and were discarded if found any.

\section{Study method}

After removing the roots, the buccal surfaces were cleaned with prophylactic paste (Dharma FL USA 58-00030) to ensure removal of extrinsic stains. Gypsum blocks were used to mount the teeth by inserting the lingual half into the blocks with the highest area of the specimen being the middle third of the buccal aspect [Figure 1].

The specimens were equally (10 in each group) and randomly divided as follows:

Group I: Ultrasonic scaling with stainless steel tip

Group II: Ultrasonic scaling with titanium tip

Group III: Hand scaling with stainless steel tip

Group IV: Hand scaling with titanium tip

\section{Instruments}

Ultrasonic instruments: Stainless steel ultrasonic G1 Scaler tip (NSK, Japan).

Titanium nitride ultrasonic G1T Scaler Tip (Woodpecker, Guilin, Guangxi, China).

Hand instruments: Stainless steel curette: Gracey no. 7/8 Hu-Friedy, Chicago, Illinois.

Titanium curette: TI 23 AS2 A. Deppeler Sa, Rolle, Switzerland.

\section{Scaling procedure}

A customized apparatus was designed and fabricated to ensure proper standardization of the scaling method. This scaling apparatus consisted of a gearbox to control the speed of the motor. A crankshaft (two cycles/s) connecting rod which is fixed

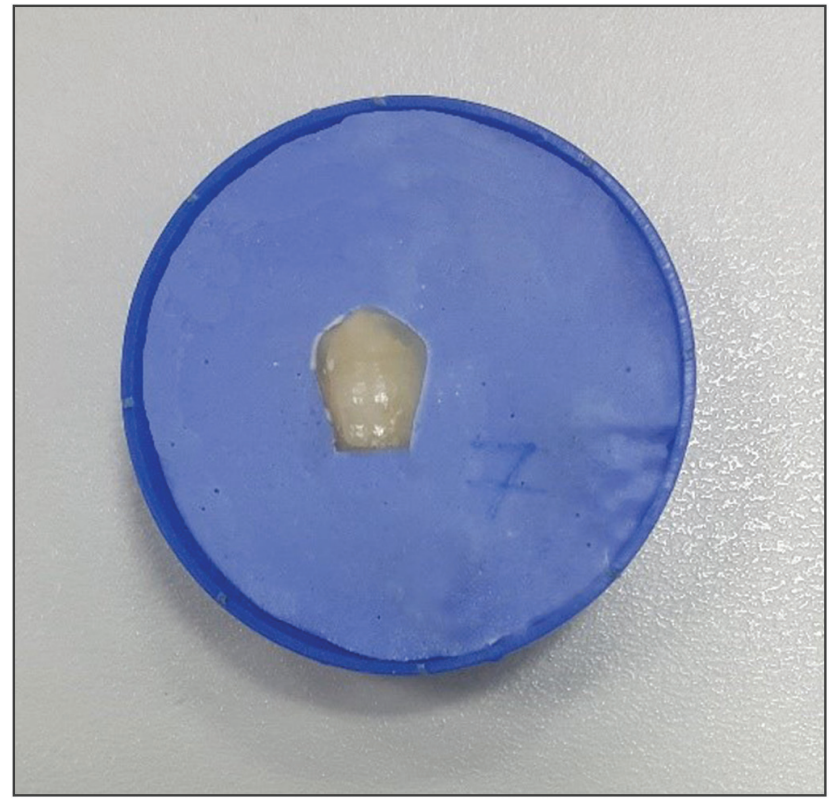

Figure 1: Gypsum blocks specimen 
to a slider for changing the movement from rotation to linear movement to deliver a consistent $5 \mathrm{~mm}$ horizontal movement, double-pane balance to simulate the forces used in manual, and ultrasonic scaling ${ }^{[22]}$ [Figure 2].

\section{Hand scaling}

The samples were mounted onto one side of the double-pane balance and attached in place using screws. Each instrument was fixed in the arm using screws with the tip engaged at a $15^{\circ}$ angle to the specimen. A constant force of $500 \mathrm{~g}$ was applied to the instrument by the vertical movement of counterweighted balance. Fifteen even strokes were made with the hand scaling instruments across the surface of each sample This representing 1 year scaling every 3 months (five times) three successive movements each. ${ }^{[23]}$

\section{Ultrasonic scaling}

The samples were mounted onto one side of the double-pane balance and attached in place using screws. An ultrasonic scaler handpiece was used intermediate power setting (level 5 of 14 grades). The scaling tips were angled $90^{\circ}$ relative to the surface of sample. A constant force of $30 \mathrm{~g}$ was applied to the ultrasonic scalar tip by the vertical movement of a counterweighed balance. ${ }^{[24]}$ A standardized $5 \mathrm{~mm}$ horizontal movement for 30 seconds was achieved. Thirty strokes were made with the ultrasonic handpiece at a speed of $2 \mathrm{~Hz}$ was achieved and operated by the control box. ${ }^{[17]}$

\section{Scanning electron microscopy analysis}

Specimens from each group were mounted on the SEM plate to examine their surfaces (Electron Microscopy Sciences, Hatfield, Pennsylvania) using the model Quanta FEG 250 (Field Emission Gun) with accelerating voltage $30 \mathrm{kV}$. All SEM images were randomized and each image was given a unique code to ensure that image analysis was performed blindly. Two research team members examined each image independently. Both examiners were initially calibrated by examining 10 SEM images (not included in the results) collaboratively to moderate and ensure consistency. The enamel surface morphology was examined on each SEM image for samples from each group after the simulated scaling procedure. Any abnormalities and/or surface defects that are not consistent with normal histological features. The intensity of surface defects was also described on each image as fine, moderate, or deep.

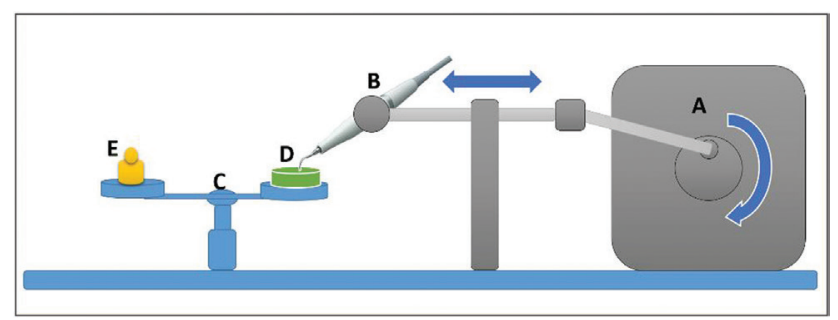

Figure 2: A schematic diagram showing the custom-made scaling and apparatus: (A) gear box, (B) instrument holder, (C) double-pane balance, (D) samples-holding pane, and (E) weight-holding pane

\section{Surface roughness measurement}

Initial surface roughness was measured using AFM Auto Probe CPResearch2 (Model: MLCT-MT-A) operated in contact mode using non-conductive silicon nitride probe, at scan area of $25 \mu \mathrm{m}$, scan rate of $1 \mathrm{~Hz}$ and number of data points $256 \times 256 \mathrm{~m}^{2}$ using proscan 1.8 software for controlling the scan parameters and IP 2.1 software for image analysis served as control. Surface roughness differences $(\Delta \mathrm{Ra})$ were calculated after measuring the values after the scaling methods.

\section{Statistical analysis}

All data were analyzed using computer software SPSS version 21 (SPSS Armonk, New York). Two-way analysis of variance (ANOVA) followed by post hoc pairwise comparisons between groups were used to analyze surface roughness differences $(\Delta \mathrm{Ra})$. A p-value less than or equal to 0.05 was considered statistically significant.

\section{RESULTS}

\section{Scanning electron microscope examination}

SEM of samples before scaling procedure revealed normal enamel surface with normal surface structures like perikymata and rod end. After scaling, group I teeth samples showed a relatively smooth enamel surface with little fine scratches. Group II showed similar surface morphology with greater change in enamel surface manifested as deep and multiple scratches on enamel surface in comparison to group I, whereas group III showed little scratches became more obvious and deeper than group I, also. Group IV samples revealed the most aggressive effect in regards to the morphology of the enamel surface in comparison to the other groups, scratches are the deepest and more destructive [Figure 3].

\section{Surface roughness}

Figure 4 shows the atomic force images before and after scaling procedures for each group.

Ultrasonic stainless steel tips clearly resulted in scraping of the enamel surfaces and loss of their original texture, leading to increased surface roughness. Its surface roughness was increased by 3.58 after scaling [Figure 4-I]. Ultrasonic titanium tips showed more aggressive and deeper scratches than the ultrasonic stainless steel tips. Its surface roughness was increased by 6.67 after scaling [Figure 4-II]. Manual stainless steel scaling showed more number of shallow irregularities than the ultrasonic stainless steel scaling. Its surface roughness was increased by 5.34 after scaling [Figure 4-III]. Manual titanium scaling caused the deepest scratches and highest change in surface roughness. Its surface roughness was increased by 8.97 after scaling [Figure 4-IV].

Two-way ANOVA revealed a statistically significant interaction in $\Delta \mathrm{Ra}$ among all groups $(P=0.042)$ [Table 1]. 
Comparisons between different experimental groups are summarized in Table 2.

\section{Effect of materials used on $\Delta \mathrm{Ra}$}

For both ultrasonic scaling and hand methods, $\Delta \mathrm{Ra}$ of titanium curettes showed a statistically significant higher difference from that of stainless steel curettes $(P=0.03$ and 0.02 , respectively).

\section{Effect of scaling methods used on $\Delta R a$}

For both stainless steel and titanium curettes, $\Delta \mathrm{Ra}$ of hand instruments showed a higher value and a statistically
A

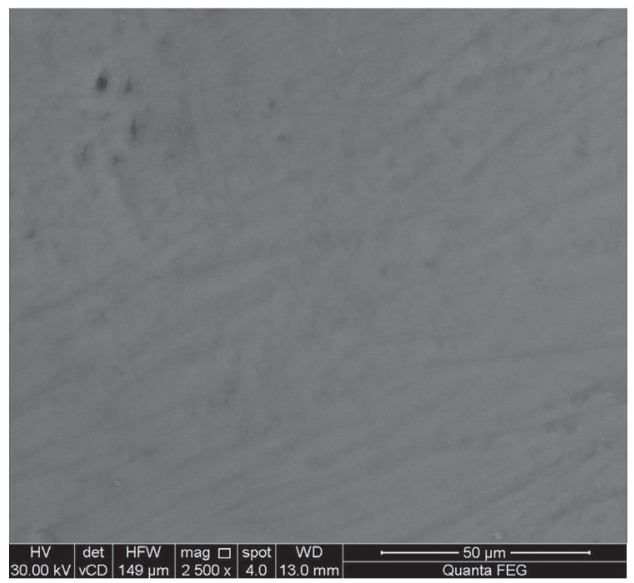

I

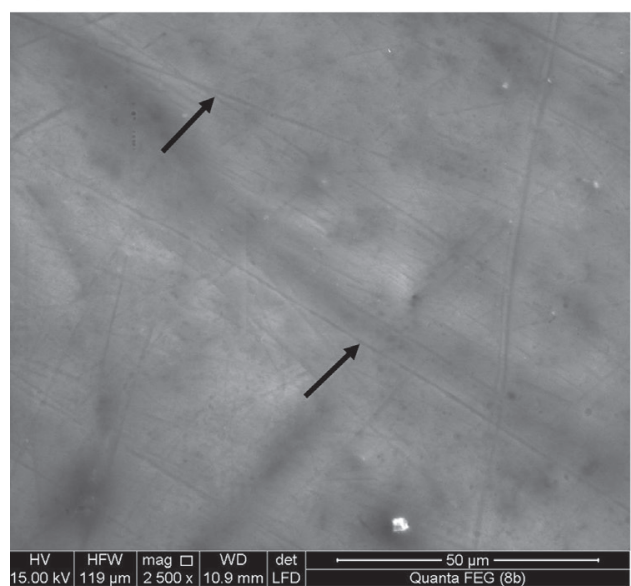

III

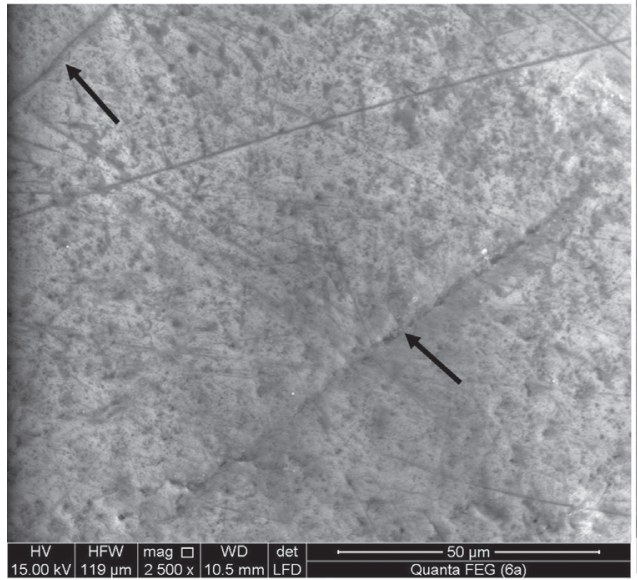

B

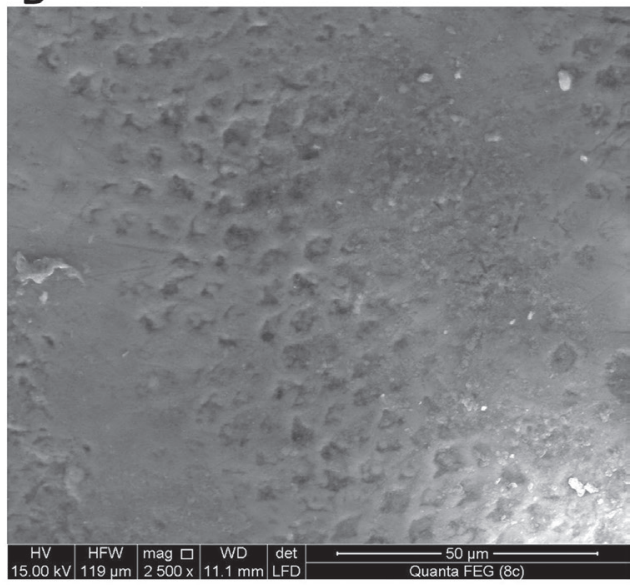

II

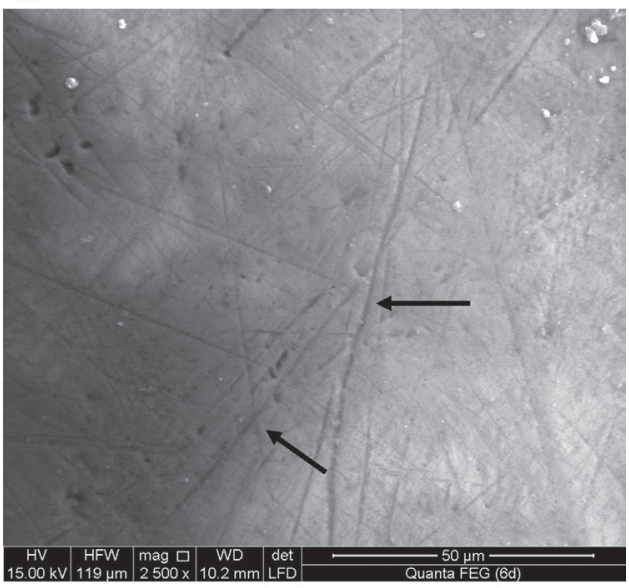

IV

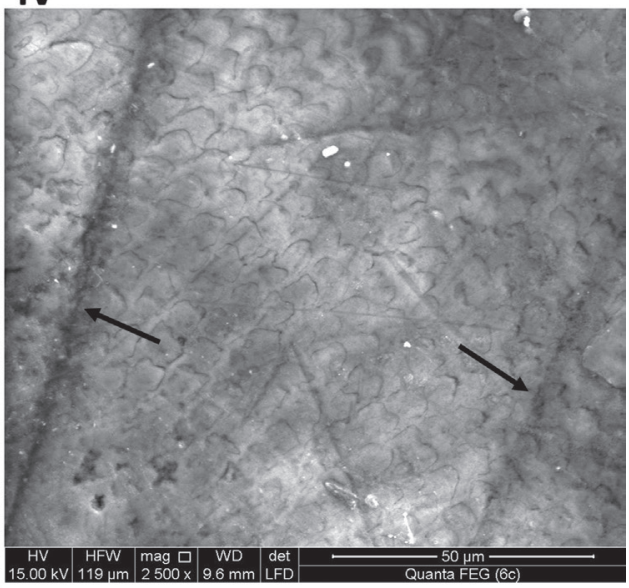

Figure 3: SEM micrographs of normal enamel surface before scaling (A) with normal structures like rod end (B). Experimental groups after the scaling procedure: group I showed smooth enamel surface with little fine scratches (arrows). Group II showed deep and multiple scratches on enamel surface (arrows), whereas group III little scratches became more obvious and deeper than group I, also. Group IV samples revealed that scratches are the deepest and more destructive (arrows). Magnification $\times 2500$ 


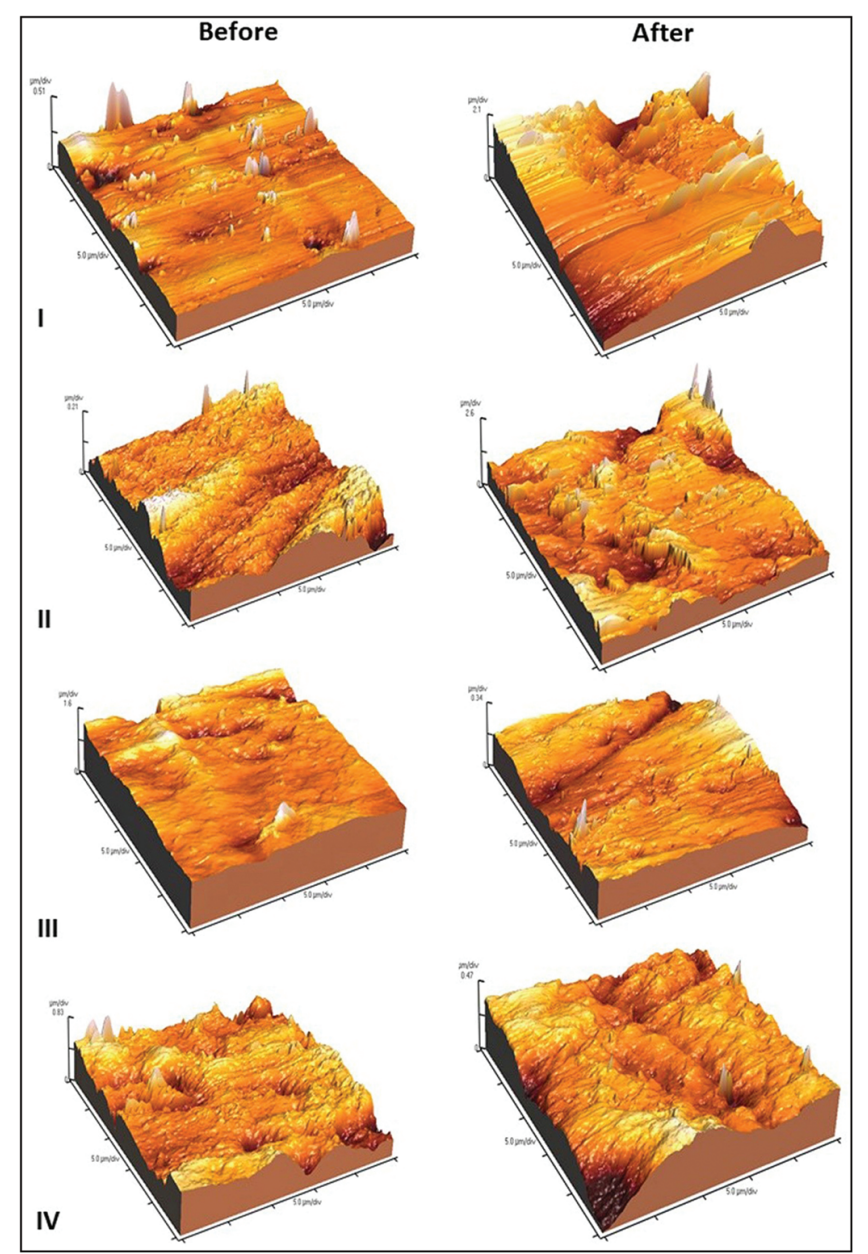

Figure 4: Atomic force images of all groups before and after scaling procedure

significant difference from that of ultrasonic tips $(P=0.02$ and 0.01 ), respectively.

\section{Discussion}

Scaling is a vital part of professional dental cleaning that is practiced by dentists and oral hygienist on a daily basis. ${ }^{[25,26]}$ It is executed using hand and power-driven ultrasonic instruments. ${ }^{[2]}$ Casarin et al. ${ }^{[28]}$ reported that ultrasonic scalers can cause roughness of tooth surfaces, a process that can be affected by working factors such as procedure time, pressure, and angulation of the scaling tip. Oral bacterial adhesion and retention is affected by the surface roughness of any hard surfaces in the oral cavity and has a significant outcome on the formation and progression of dental plaque as well as influencing discoloration of esthetic restorations.. ${ }^{[29-31]}$ Consequently, this in vitro study has been performed to detect the effect of routine scaling using hand or ultrasonic tips on the enamel surface roughness $(\mathrm{Ra})$.

Instrumentation of the tooth, until it is clean, is highly operator-dependent and many operating parameters such as load and contact angle might affect the outcome. ${ }^{[32]}$ In this study, instrumentation was performed using a specially designed apparatus to control all variables (time, pressure, and tip angulation), whereas testing other factors which are the material and method of scaling procedure.

The use of SEM for evaluating surface topography and assessing the state of dental tissues surfaces has been widely used in previous studies. ${ }^{[21,32-35]}$ For, high-resolution surface investigation, AFM was used. AFM analysis was proposed to provide qualitative and quantitative data on the detailed description of various dental materials. ${ }^{[36]}$ AFM recreate a 3-dimensional image of the surface topography in real time. Analysis of these data sets can be used with specific software to obtain all the relevant data related to the examined surface in a quantitative form. Moreover, another important feature of AFM is that it allows the surface features to be visualized in an enhanced with better details. ${ }^{[36]}$

In this study, surface roughness increased in all specimens after scaling procedure. Group IV (hand scaling using titanium curettes) showed the highest mean surface roughness difference $(\Delta \mathrm{Ra})$, whereas group I (ultrasonic scaling using stainless steel tips) showed the least $\Delta$ Ra. Regarding the effect of the material of instrument on the surface roughness $(\Delta \mathrm{Ra})$ readings; titanium instruments caused a statistically significant increase in mean surface roughness than the stainless steel instruments in both hand $(P=0.02)$ and ultrasonic $(P=0.03)$ groups. This was qualitatively confirmed by SEM analysis which showed enamel specimens of the titanium groups to have deep surface scratches and grooves. This may be attributed to the increased hardness of the titanium instruments $(\sim 751.9 \mathrm{MPa})$ compared to the stainless-steel instruments $(\sim 591.6 \mathrm{MPa})^{[37]}$ which in return causes more deleterious effect on enamel. Tamura et al. ${ }^{[38]}$ reported that the Vickers hardness of titanium nitride was 1300 . This was in contradiction to Vigolo et al. ${ }^{[39]}$ who recorded equal increase in the median surface roughness profile value for both steel curette and titanium curette.

As for the effect of scaling method, this study revealed that hand scaling method caused more increase in enamel roughness and more harmful changes to enamel surface than that of ultrasonic scaling method. The increase in mean surface roughness was statistically significant for the titanium instruments and for the stainless steel instruments. SEM analysis revealed larger scratches on the enamel surface of specimens of the hand instruments groups. This difference might hereby be explained by the higher pressure usually used for hand instrumentation ${ }^{[40]}$ than that used for ultrasonic scaling, ${ }^{[4]}$ to simulate the clinical situation. This results in deep scratches as well as striae in the hand group. Coinciding results were found in previous investigations. ${ }^{[2,43]}$ Graetz et al. ${ }^{[33]}$ in a comparative assessment of the possible efficacy, benefits and harms of newly developed double gracey curettes (GRA) and sonic (AIR) and ultrasonic instruments (TIG) 


\begin{tabular}{|c|c|c|c|c|c|c|c|c|c|}
\hline \multirow[t]{2}{*}{$\begin{array}{l}\text { Scaling } \\
\text { method }\end{array}$} & \multirow[t]{2}{*}{ Material } & \multirow[t]{2}{*}{ Mean $\Delta \mathrm{Ra}$} & \multirow[t]{2}{*}{ SD } & \multicolumn{3}{|c|}{ df } & \multicolumn{2}{|c|}{$\begin{array}{c}\text { 95\% Confidence interval for } \\
\text { mean }\end{array}$} & \multirow[t]{2}{*}{$\begin{array}{l}\text { ANOVA } \\
P \text { Value }\end{array}$} \\
\hline & & & & $\begin{array}{l}\text { Between } \\
\text { groups }\end{array}$ & Within groups & Total & Lower Bound & Upper Bound & \\
\hline \multirow[t]{2}{*}{ Ultrasonic } & Stainless steel & 3.58 & 0.3 & \multirow[t]{2}{*}{3} & \multirow[t]{2}{*}{36} & \multirow[t]{2}{*}{39} & 3.31 & 3.84 & \multirow[t]{2}{*}{$0.042^{*}$} \\
\hline & Titanium & 6.67 & 0.25 & & & & 6.36 & 6.97 & \\
\hline \multirow[t]{2}{*}{ Hand } & Stainless steel & 5.34 & 0.42 & & & & 5.01 & 5.66 & \\
\hline & Titanium & 8.97 & 0.76 & & & & 8.70 & 9.23 & \\
\hline
\end{tabular}

*Significant at $P<0.05$

\begin{tabular}{lcc}
\hline $\begin{array}{l}\text { Table 2: Mean } \Delta \mathrm{Ra} \text { and } \boldsymbol{P} \text { values comparing } \\
\text { experimental groups }\end{array}$ & different \\
\hline Group & Mean difference & $\boldsymbol{P}$ Value \\
\hline Group I vs. Group II & -3.09 & $P=0.03^{*}$ \\
Group I vs. Group III & -1.76 & $P=0.02^{*}$ \\
Group I vs. Group IV & -5.39 & $P=0.01^{*}$ \\
Group II vs. Group III & 1.33 & $P=0.42$ \\
Group II vs. Group IV & -2.30 & $P=0.01^{*}$ \\
Group III vs. Group IV & -3.63 & $P=0.02^{*}$ \\
\hline *Signifcantat $P<0.05$ & &
\end{tabular}

*Significant at $P<0.05$

where the surface roughness was higher with GRA than the AIR and TIG. This increase in surface roughness was attributed to the repetitive overlapping working strokes, which can cause irregular patterns and deep scratches on the surface. Also Mittal et al. ${ }^{[44]}$ in a comparison of the effectiveness of different ultrasonic (a piezoelectric device and a magnetostrictive ultrasonic device) and a periodontal curette on calculus removal and surface roughness where the curette produced the rougher surfaces than ultrasonic devices, many instrument scratches, and deep gouges were observed and a significant amount of the dentine layer was removed, the surface cracks were maximum in this group.

The results of this study suggest changes in the enamel surface topography and roughness after using titanium and stainless steel instruments for prophylactic periodontal treatment. Moreover, different methods of scaling, hand, and ultrasonic, resulted in changes in the morphology and roughness of enamel surface. Therefore titanium curettes and tips are not suitable for the use in scaling procedures on enamel surface.

Further studies, including clinical trials, of the effects of novel periodontal instruments onto hard dental tissues topography and into the most desirable approach for intraoral debridement would be desirable to clarify the significance of the observations made in this in vitro study.

\section{Conclusion}

Scaling using ultrasonic stainless steel tips produced the least amount of surface roughness and damage, whereas titanium curettes and tips produced more aggressive changes on the enamel surface in vitro.

\section{Acknowledgement}

Not applicable.

\section{Financial support and sponsorship \\ Not applicable. \\ Conflicts of interest \\ There are no conflicts of interest.}

\section{Ethical policy and Institutional Review board statement} Ethical approval was obtained from the Research Ethics Committee at Suez Canal University (Suez- REC 54/2018).

\section{Data availability statement}

The data that support the findings of this study are available from the corresponding author, on reasonable request.

\section{RefERENCES}

1. Hall-Stoodley L, Stoodley P. Evolving concepts in biofilm infections. Cell Microbiol 2009;11:1034-43.

2. Kolenbrander PE, Palmer RJ Jr, Periasamy S, Jakubovics NS. Oral multispecies biofilm development and the key role of cell-cell distance. Nat Rev Microbiol 2010;8:471-80.

3. Nobbs AH, Jenkinson HF, Jakubovics NS. Stick to your gums: Mechanisms of oral microbial adherence. J Dent Res 2011;90:1271-8.

4. Makkar H, Reynolds MA, Wadhawan A, Dagdag A, Merchant AT, Postolache TT. Periodontal, metabolic, and cardiovascular disease: Exploring the role of inflammation and mental health. Pteridines 2018;29:124-63.

5. Saini R, Saini S, Sharma S. Biofilm: A dental microbial infection. J Nat Sci Biol Med 2011;2:71-5.

6. Koo H, Allan RN, Howlin RP, Stoodley P, Hall-Stoodley L. Targeting microbial biofilms: Current and prospective therapeutic strategies. Nat Rev Microbiol 2017;15:740-55.

7. Velsko IM, Overmyer KA, Speller C, Klaus L, Collins MJ, Loe L, et al. The dental calculus metabolome in modern and historic samples. Metabolomics 2017;13:134.

8. Velsko IM, Fellows Yates JA, Aron F, Hagan RW, Frantz LAF, Loe L, et al. Microbial differences between dental plaque and historic dental calculus are related to oral biofilm maturation stage. Microbiome 2019;7:102.

9. Do T, Devine D, Marsh PD. Oral biofilms: Molecular analysis, challenges, and future prospects in dental diagnostics. Clin Cosmet Investig Dent 2013;5:11-9.

10. Liu Y, Ren Z, Hwang G, Koo H. Therapeutic strategies targeting cariogenic biofilm microenvironment. Adv Dent Res 2018;29:86-92.

11. American Academy of Periodontology. Comprehensive periodontal therapy: A statement by the American Academy of Periodontology. J Periodontol 2011;82:943-9. 
12. Deas DE, Moritz AJ, Sagun RS Jr, Gruwell SF, Powell CA. Scaling and root planing vs. Conservative surgery in the treatment of chronic periodontitis. Periodontol 2000 2016;71:128-39.

13. Zafar MS. Comparing the effects of manual and ultrasonic instrumentation on root surface mechanical properties. Eur J Dent 2016;10:517-21.

14. Kumar P, Das SJ, Sonowal ST, Chawla J. Comparison of root surface roughness produced by hand instruments and ultrasonic scalers: An in vitro study. J Clin Diagn Res 2015;9:ZC56-60.

15. Yaghini J, Naghsh N, Attaei E, Birang R, Birang E. Root surface roughness after scaling and root planing with er:YAG laser compared to hand and ultrasonic instruments by profilometry. J Dent (Tehran) 2015;12:899-905.

16. Vyas N, Manmi K, Wang Q, Jadhav AJ, Barigou M, Sammons RL, et al. Which parameters affect biofilm removal with acoustic cavitation? A review. Ultrasound Med Biol 2019;45:1044-55.

17. Casarin RC, Ribeiro FV, Sallum AW, Sallum EA, Nociti FH Jr, Casati MZ. Root surface defect produced by hand instruments and ultrasonic scaler with different power settings: An in vitro study. Braz Dent J 2009;20:58-63.

18. Flemmig TF, Petersilka GJ, Mehl A, Hickel R, Klaiber B. The effect of working parameters on root substance removal using a piezoelectric ultrasonic scaler in vitro. J Clin Periodontol 1998;25:158-63.

19. Moghare Abed A, Tawakkoli M, Dehchenari MA, Gutknecht N, Mir M. A comparative SEM study between hand instrument and er:YAG laser scaling and root planing. Lasers Med Sci 2007;22:25-9.

20. Kim SY, Kang MK, Kang SM, Kim HE. Effects of ultrasonic instrumentation on enamel surfaces with various defects. Int J Dent Hyg 2018;16:219-24.

21. Sirinirund B, Garaicoa-Pazmino C, Wang H-L. Effects of mechanical instrumentation with commercially available instruments used in supportive peri-implant therapy: An in vitro study. Int $\mathbf{J}$ Oral Maxillofac Implants 2019;34:1370-8.

22. Shamel M, Al-Ankily MM, Bakr MM. Influence of different types of whitening tooth pastes on the tooth color, enamel surface roughness and enamel morphology of human teeth. F1000Res 2019;8:1764.

23. Coldiron NB, Yukna RA, Weir J, Caudill RF. A quantitative study of cementum removal with hand curettes. J Periodontol 1990;61:293-9.

24. Covani U, Giacomelli L, Krajewski A, Ravaglioli A, Spotorno L, Loria $\mathrm{P}$, et al. Biomaterials for orthopedics: A roughness analysis by atomic force microscopy. J Biomed Mater Res A 2007;82:723-30.

25. Bellows J. Periodontal Equipment, Materials, and Techniques. Small Animal Dental Equipment, Materials and Techniques. Singapore: Wiley Blackwell; 2004. p. 115-73.

26. Caiafa A, Tutt C. Canine infectious, inflammatory and immunemediated oral conditions. In: Deeprose J, Crossley D, editors. BSAVA Manual of Canine and Feline Dentistry; 2007. p. 96-125.

27. Cobb CM. Clinical significance of non-surgical periodontal therapy: An evidence-based perspective of scaling and root planing. J Clin Periodontol 2002;29:6-16.
28. Casarin R, Pinto F, Nociti F, Sallum E, Sallum A, Casati M. Assessment of ultrasonic root surface scaling with different power settings. Roughness evaluation. Braz J Oral Sci 2006:58-63.

29. Hao Y, Huang X, Zhou X, Li M, Ren B, Peng X, Cheng L. Influence of dental prosthesis and restorative materials interface on oral biofilms. Int J Mol Sci 2018;19:3157.

30. Huacho PMM, Nogueira MNM, Basso FG, Jafelicci Junior M, Francisconi RS, Spolidorio DMP. Analyses of biofilm on implant abutment surfaces coating with diamond-like carbon and biocompatibility. Braz Dent J 2017;28:317-23.

31. Huang R, Li M, Gregory RL. Bacterial interactions in dental biofilm. Virulence 2011;2:435-44.

32. Chien HC, Ye DQ. Microscopic view of scaling influence on the root, using different power and time settings. Quintessence Int 2016;47:559-68.

33. Graetz C, Plaumann A, Wittich R, Springer C, Kahl M, Dörfer CE, et al. Removal of simulated biofilm: An evaluation of the effect on root surfaces roughness after scaling. Clin Oral Investig 2017;21:1021-8.

34. Yukna RA, Vastardis S, Mayer ET. Calculus removal with diamondcoated ultrasonic inserts in vitro. J Periodontol 2007;78:122-6.

35. Vastardis S, Yukna RA, Rice DA, Mercante D. Root surface removal and resultant surface texture with diamond-coated ultrasonic inserts: An in vitro and SEM study. J Clin Periodontol 2005;32:467-73.

36. Pantić M, Mitrovic S, Babic M, Jevremović D, Kanjevac $T$, Dzunic D, et al. AFM surface roughness and topography analysis of lithium disilicate glass ceramic. Tribol Indus 2015;37:391-9.

37. Steele JG, McCabe JF, Barnes IE. Properties of a titanium nitride coating for dental instruments. J Dent 1991;19:226-9.

38. Tamura Y, Yokoyama A, Watari F, Uo M, Kawasaki T. Mechanical properties of surface nitrided titanium for abrasion resistant implant materials. Mater Trans 2002;43.

39. Vigolo P, Buzzo O, Buzzo M, Mutinelli S. An in vitro evaluation of alumina, zirconia, and lithium disilicate surface roughness caused by two scaling instruments. J Prosthodont 2017;26:129-35.

40. Checketts MR, Turkyilmaz I, Asar NV. An investigation of the effect of scaling-induced surface roughness on bacterial adhesion in common fixed dental restorative materials. J Prosthet Dent 2014;112:1265-70.

41. Seol HW, Heo SJ, Koak JY, Kim SK, Baek SH, Lee SY. Surface alterations of several dental materials by a novel ultrasonic scaler tip. Int J Oral Maxillofac Implants 2012;27:801-10.

42. Santos FA, Pochapski MT, Leal PC, Gimenes-Sakima PP, Marcantonio E Jr. Comparative study on the effect of ultrasonic instruments on the root surface in vivo. Clin Oral Investig 2008; 12:143-50.

43. Gehrke P, Spanos E, Fischer C, Storck H, Tebbel F, Duddeck D. Influence of scaling procedures on the integrity of titanium nitride coated CAD/CAM abutments. J Adv Prosthodont 2018;10:197-204

44. Mittal A, Nichani AS, Venugopal R, Rajani V. The effect of various ultrasonic and hand instruments on the root surfaces of human single rooted teeth: A planimetric and profilometric study. J Indian Soc Periodontol 2014;18:710-7. 
Copyright of Journal of International Oral Health is the property of International Society of Preventive \& Community Dentistry and its content may not be copied or emailed to multiple sites or posted to a listserv without the copyright holder's express written permission.

However, users may print, download, or email articles for individual use. 